\title{
Postneoadjuvant Therapy Stage IVA Esophageal Adenocarcinoma AJCC v8
}

National Cancer Institute

\section{Source}

National Cancer Institute. Postneoadjuvant Therapy Stage IVA Esophageal

Adenocarcinoma A/CC v8. NCI Thesaurus. Code C133439.

Stage IVA includes: (T4a, N1-2, M0); (T4a, NX, M0); (T4b, N0-2, M0); (Any T, N3, M0).

T4a: Tumor invades the pleura, pericardium, azygos vein, diaphragm, or peritoneum.

T4b: Tumor invades other adjacent structures, such as the aorta, vertebral body, or airway. NX: Regional lymph nodes cannot be assessed. N0: No regional lymph node metastasis. N1: Tumor with metastasis in one or two regional lymph nodes. N2: Tumor with metastasis in three to six regional lymph nodes. N3: Tumor with metastasis in seven or more regional lymph nodes. M0: No distant metastasis. (AJCC 8th ed.) 